\title{
UK ENTERPRISE POLICY - A TWIST ON REAL ESTATE, AUSTERITY AND PLANNING
}

\author{
M.G. Lloyd and D. Peel \\ School of the Built Environment, University of Ulster, UK \\ $\underline{\text { mg.lloyd@ulster.ac.uk and d.peel@ulster.ac.uk }}$
}

\subsection{Introduction}

Times and circumstances change, and sometimes prevailing ideas and thinking do not manage to keep up with those changes. Sometimes an older idea is re-invented and brought back into play - even though context and conditions may have changed. This paper considers such a case - the political reprise of the enterprise zone idea in the UK which was initially designed to address local and regional issues associated with an economic downturn and poorly performing real estate markets in the early 1980s. The enterprise zone model of regeneration was first introduced as a response to the then prevailing depressed economic circumstances and was presented as a way of triggering economic growth and job creation in specific localities or zones. It was introduced as an experiment and the designations lasted until the mid 1990s.

In the 2010s economic conditions in the UK are held to be very similar to those prevailing in the early 1980 s. There is an evident recession, unemployment, deflated demand, and an over-supply of property. Over and above this, in the UK the policy response is predicated on austerity - with fiscal restraint and public expenditure cutback. Yet there is also a very marked geographical distribution of these circumstances and this has prompted an interest in the earlier enterprise zone idea. Indeed, in 2012 the enterprise zone model is once again being put into place to address the current economic and real estate downturn in the UK.

There is a twist in the tale, however, as devolution in the UK has allowed the new devolved political administrations in Scotland, Wales and Northern Ireland wider scope for 'experimentation' around economic policy at large and the relevance of the enterprise zone concept in particular. Devolution took place in the UK in 1999 following political debates about the consequences of the previously unitary UK state which was governed from Westminster and represented a centralised government structure for policy making and implementation. Devolution allowed new political arrangements which better reflected the different economic, cultural and geographical experiences, customs and traditions across the UK. The Westminster model was replaced by devolved administrations in Scotland, Wales, Northern Ireland and in England. The process of devolution was differentiated with respect to the institutions, organisations and powers involved. This paper documents the different interpretations of the enterprise zone idea contrasting developments in England and Scotland - and considers the lessons for regeneration elsewhere. 


\subsection{The first UK enterprise zone experiment}

The enterprise zone story starts with the Local Government, Planning and Land Act 1980 which was introduced at a time when a (newly elected) Conservative government was seeking to impose its political values and priorities on the UK economy which was experiencing severe recessionary pressures (Lloyd \& Botham, 1985). Structural industrial restructuring, regional economic imbalances and localised concentrations of unemployment and disinvestment combined to create a difficult context. The government of the day expressed two strong viewpoints on the nature of the UK economy and the appropriateness of its policy responses.

First, it considered that that the previously prevailing Keynesian inspired spending and regulatory interventions had failed to address the complex issues involved in securing urban and regional regeneration and development; and indeed, such interventions were held to have exacerbated the overall damaged economic conditions. It was held that this pointed to evidence of government failure, crowding out, and inefficient public sector decision making which inhibited any chance of economic recovery (Lloyd \& Botham, 1985). In effect, an alternative approach was held to be required. Second, the government asserted the case for a pro market business led approach as more appropriate to the economic conditions and policy management of the day. Moreover, the government took the view that real estate or land and property development was the key to achieving economic stability, encouraging private sector investment and securing economic recovery.

This duality of reasoning led directly to the idea of creating enterprise zones - which promoted pro business activity allied to land and property development, and which shifted to a reliance on minimal government regulation and spending. The 1980 legislation introduced enterprise zones - which had been proposed in various policy circles, drawing on experiences of free ports or entrepôts elsewhere in the world, such as Hong Kong (Hall, 1982). Enterprise zones brought together tightly designated areas and a portfolio of fiscal incentives, streamlined land use planning and administrative reliefs. The measure provided various incentives over a ten-year life span. These included 100\% allowances for corporation and income tax purposes for capital expenditure on industrial and commercial buildings; exemption from property rates on industrial and commercial buildings; employer exemptions from industrial training levies and from the requirement to supply information to Industrial Training Boards; applications from firms in the zones for certain customs facilities to be processed as a matter of priority; reduced government requests for statistical information; and a simplified planning scheme to enable an automatic right of development for specified land uses. When taken together this incentive regime deliberately set out to create a new local property led economic agenda (Jones et al., 2002). This represented an explicit turn in local and regional economic policy for regeneration in the UK from intervention, regulation and expenditure to a more liberal market regime.

Whilst the emphasis on market infused incentives is perhaps understandable given the prevailing neo-liberal economic ideology and the political priorities being asserted - it raised questions about the emphasis on real estate 
as the vehicle to deliver the intentions of the zones. First, at that time, and as a consequence of its industrial and economic restructuring, the UK was characterised by derelict and redundant property, contaminated land and infrastructure deficits - particularly in the under-performing regional and urban economies. In other words, there was a deficit in available high quality, bespoke office and commercial accommodation to provide an opportunity for new business ventures, growth and diversification and the attraction of inward investment. Second, the political thinking of the time held the view that supply would create its own demand - and that by providing new space then business would respond positively. Third, real estate investment and development would assume a potent, visible image of physical change taking place across the UK economy.

Between, 1982 and 1996 the enterprise zone 'experiment' was rolled out - with some 36 zones designated across the UK in a range of localities. Most were in areas severely damaged by industrial change and closure - as with the Singer Sewing Machine factory in Clydebank, Scotland. Others comprised pockets of smaller sites which were then assembled together as a patchwork zone to enable their regeneration, as in Dundee, Scotland. Research into the effects of the property led measure showed that, whilst the designations led to marginal improvements in some designated areas, in totality enterprise zones did not facilitate a sustainable recovery in investment and employment. Indeed, a number of studies pointed to displacement effects and the destabilising effects on enterprise zones' local and regional economic hinterlands (PA Cambridge Economic Consultants, 1987). Concerns were raised about the overall sustainability of the approach (Jones et al., 2002) and about a zone's real contribution to enterprise creation (Talbot, 1994). Notwithstanding these criticisms, the idea remained an important influence - leading to a second phase of interest in the idea of simplified planning zones. This element of the original enterprise zone concept was intended to allow local authorities to free up areas from planning restrictions (Lloyd, 1992). No tax relief was provided but the measure again reflected the focus of government thinking on market led solutions to economic problems at this time.

\subsection{Devolution And Economic Ideas}

The Conservative government was followed by a Labour administration which, whilst retaining many of the liberal market economic values of the preceding administration, did not actively pursue the enterprise zone experiment further. Alternative ideas were promoted, for example, particularly around the idea of partnerships in local and regional development. Importantly, however, the new Labour administration enabled political devolution to take place (Peel \& Lloyd, 2006). The Scottish Parliament, The Welsh Assembly and the Northern Ireland Assembly were able to bring some regional distinctiveness to their policies, although the Westminster Government retained overall strategic authority.

This new relative political autonomy allowed the nation-regions to experiment with their own reforms to planning, regeneration, governance and regeneration. These important public policy areas fell into their specific devolved remits. The underlying rationale of devolution was to enable Scotland, Northern Ireland and Wales to devise policies 
and instruments more attuned to their own specific conditions. Alternative arrangements were put in place for the English sub national areas. The devolved regions began to draft their individual spatial planning approaches, for example, to ensure that strategic planning and land use agendas were an intrinsic part of their overall policy portfolio. Scotland, for example, began a process of modernisation of its statutory land use planning system to create a more robust strategic framework for decision making through a new National Planning Framework. This period of innovation characterised the 2000s and led to divergent policy approaches across the devolved UK.

In 2007, there was a change in the UK political context and a Conservative-Liberal Democrat coalition government was elected into office at Westminster. Notwithstanding devolution, this created a new landscape for economic values and ideas. These can permeate the devolved areas. The election coincided with changing economic circumstances - the onset of the credit crunch, the financial crisis, and a recession. The new coalition government chose to put into effect a policy agenda based on public expenditure cutbacks, austerity and a shift to business led policy. These circumstances mirrored the position in the 1980s and a neo-liberal economic agenda was put in place. The effects of this ideological policy regime are evident across a range of public service sectors - education, health and local government. The retrenchment and hollowing out of the government apparatus is also reminiscent of the 1980s when the neo-liberal thinking first expressed itself in its modern idiom. Part of this replaying of older ideas has included the reprise of the enterprise zone idea in England.

\subsection{Mark 2 Enterprise Zones}

In England, the creation of a Mark 2 enterprise zone model was announced as part of the coalition government's March 2011 Budget. The Chancellor of the Exchequer George Osborne announced 21 zones to be designated. Subsequently and perhaps surprisingly given the devolved political context, he announced the designation of new enterprise zones in Wales and Scotland. The Mark 2 enterprise zones involve slightly different measures to the earlier model but essentially retain the same blend of fiscal incentives, simplified planning arrangements and other administrative relief. In effect, in England, there is a direct reprise of the older idea - suggesting that the Westminster based administration has ignored the lessons from the Mark 1 enterprise zone experiment. This point is important because the land and property context in many of current designated zones is now very different to that which had previously prevailed in the 1980s. Whilst as then there was a shortage of business accommodation there is now an effective over supply of office space and business premises in many areas - a consequence of the continuing recession. This suggests that the focus of the Mark 2 enterprise zone initiative may be diluted as the real problem in such areas rests on under investment in industrial capacity, a lack of skills and support for new form start-ups, diversification, and marketing to attract new inward investment.

Elsewhere in the devolved UK, however, there are variations on the enterprise zone theme beginning to become apparent - particularly in Scotland. Since devolution, Scotland has defined a distinctive approach to its arrangements for land use planning, economic development and regeneration and governance. In the context of statutory land use 
planning, for example, Scotland has moved to create a modern strategic planning hierarchy. The apex of this new proportionate and front loaded approach in terms of community engagement is the National Planning Framework which sets the statutory for planning and development decision making across the Scottish economy and sets strategic priorities for infrastructure provision and relations between its sub-national economies (Peel \& Lloyd, 2007). Importantly, Scotland also reshaped its central-local government affairs to bring planning to the centre as a delivery vehicle for wider economic ambitions.

A continuing focus on reform and modernisation of governance arrangements across the UK is evident in the context of the enterprise zone model. Whilst this idea is being promulgated as appropriate to addressing prevailing economic challenges, Scotland has reworked the enterprise zone concept to meet its own policy ambitions and circumstances. Rather than follow the geographically based Mark 1 enterprise zone model where areas are designated within which all economic activities apply, Scotland has devised a more sophisticated approach based on the growth potential of specific economic sectors. This is a deliberate way of avoiding the deadweight consequences of relying on the designation of geographical zones.

\subsection{Mark 3 Enterprise Zones}

In Scotland the enterprise area model may be considered the Mark 3 version of enterprise zones. In practice, four enterprise areas are to be created in Scotland with an emphasis on defined industries considered to have potential to create new employment opportunities, stimulate private investment, and boost economic growth (Scottish Government, 2011). These sectors are the Life Sciences Enterprise Area; the Low Carbon / Renewables North Enterprise Area; the Low Carbon / Renewables East Enterprise Area; and the General Manufacturing and Growth Sectors Enterprise Area. The logic is clear; enterprise areas are sector based, from which specific locations are determined, and then the Scottish Government will go on to agree the specific incentives that will be offered to encourage private investment at each of the sites in the individual enterprise areas. The incentives provided will be customised to the characteristics of each site and may include a combination of reduced business rates, and a streamlined planning process based on a planning protocol with the Convention of Scottish Local Authorities.

Reflecting the strategic ethos of the National Planning Framework, the enterprise areas identify the strategic locations in key sectors with clear, achievable opportunities for development in the short term. The enterprise areas were identified following an assessment process which identified the development sites which it was considered could best generate early employment opportunities and boost economic recovery. Attention was paid to the potential to maximise strategic manufacturing opportunities in Scotland's growth sectors and industries, whilst incorporating supply chain and local support opportunities locally and across Scotland. The assessment criteria included evidence of market failure or barriers to growth which enterprise area incentives could help remove; evidence of the opportunity for additionality in new job creation; evidence of the need for improved local economic performance; and the development challenges which could prevent early site delivery. 
It is intended that a range of incentives will be made available to encourage private investment at each enterprise area site. These incentives could potentially include business rates discounts and a streamlined planning process. Assistance will be made available in marketing the enterprise areas internationally, while the Government will seek to maximise any opportunities presented to make enterprise areas as attractive as possible. In addition, engagement with the UK Government is ongoing to explore the scope to offer enhanced capital allowances for investment in plant and machinery, as an alternative to business rates discounts, at a limited number of enterprise area sites.

This new interpretation of the enterprise zone model is becoming evident elsewhere. In Wales, for example, new enterprise zones are being established - as at St Athan - with a focus on the aerospace sector and related commercial activities. This approach again focuses on the industrial sector or activity and then maps the sites involved. The incentives follow the activity not the area itself. Northern Ireland, however, is experiencing a more complex and protracted debate around enterprise zones as it is bound up with the broader corporation tax question relative to the fiscal arrangements in the Republic of Ireland.

\subsection{Concluding Remarks}

What is significant about this rethinking of the earlier enterprise zone experiment in Scotland? First, the adaptation of the Mark 1 model would suggest that (as a consequence of political devolution) relatively more sophisticated approaches are being taken to the design of economic instruments within specific national-regional contexts. Second, it would appear that more critical attention is being paid to the complexities of the devolved economies and of the positive support needed to support and nurture industries with identified growth potential. Enterprise areas in Scotland are clearly related to sectors viewed as having potential within the Scottish Government's broader economic strategy. The geographic dimension is carefully sifted in light of the available evidence for its prospective capacity to develop. Enterprise areas involve specific incentives that will be offered to encourage private investment at each of the identified sites. In devising more sensitive approaches to economic policy implementation it would appear that a more robust and strategic understanding is emerging of the strengths and weaknesses of the industrial base in different areas. This is a lesson for elsewhere. Economic activity is not even over time or space nor indeed is it equally capable of innovation and creative development. The new ideas emerging in Scotland with a twist on an older idea suggest the beginnings of a better fit between policy and socio-economic circumstances.

\subsection{References}

Hall, P. (1982). Enterprise Zones: a justification. International Journal of Urban and Regional Research 6, 415-421. Jones, C., Dunse, N. \& Martin, D. (2002). The property market impact of British enterprise zones. Journal of Property Research, 20 (4), 343-369. 
Lloyd, M.G. \& Botham, R. (1985). The ideology and implementation of Enterprise Zones in Britain. Urban Law and Policy, 7 (1), 33-55.

Lloyd, M.G. (1992). Simplified Planning Zones, land development, and planning policy in Scotland. Land Use Policy, 9, 249-258.

PA Cambridge Economic Consultants (1987). An evaluation of the Enterprise Zone experiment. London, HMSO, Department of the Environment.

Peel, D. \& Lloyd, M.G. (2006). The Twisting Paths to Planning Reform in Scotland. International Planning Studies, $11(2), 89-107$.

Peel, D. \& Lloyd, M.G. (2007). Neo-traditional Planning: Towards a New Ethos for Land Use Planning? Land Use Policy 24 (2) 396-403.

Scottish Government (2011). The Government Economic Strategy. Edinburgh: The Scottish Government.

Talbot, J. (1994) Have Enterprise zones encouraged enterprise? Some empirical evidence from Tyneside, Regional Studies, 22 (6), 507-514. 